\title{
NOTA SÔBRE VARIAÇÃO ESPECÍFICA EM CERATIUM FURCA DUJARDIN, DO PLANCTON DO LITORAL PAULISTA.
}

\author{
João de Azevedo Souza.
}

O Instituto Paulista de Oceanografia, por intermédio da Secção da Fauna Marítima, vem efetuando estudos planctonológicos na costa paulista, com o objetivo de avaliar a produtividade de suas águas.

As investigações tiveram início na baía de Santos, no canai da Bertioga e na região do rio Casqueiro, Municipio de São Vicente. O estudo quantitativo efetuado nêsses três setôres foi muito prejudicado em virtude das águas dessas regiões serem altamente poluidas, excessão feita das do canal da Bertioga que recebem contingentes de águas mais puras, provenientes da barra do mesmo nome. À vista disso, a direção do estabelecimento procurou instalar duas bases de pesquisas em pontos mais adequados do litoral bandeirante: uma, em S. Sebastião, no litoral norte, e, outra, em Cananéia no extremo oposto. Dessa maneira, na zona circunvizinha do nosso maior porto, efetuam-se. de preferência, estudos qualitativos, destinados a servir de termo dc comparação aos que se fazem na costa norte e sul e a promover o inventário de invertebrados marinhos do litoral do E. de S. Paulo.

As coletas são feitas durante três ou mais vezes por mês, anotando-se, nos respectivos protocolos, todos os dados que lhes dizem respeito.

Dentre o material que merece a nossa cuidadosa atençáo, os Dinoflagelados figuram em plano de destaque. Quasi todos os autores, que dêles se têm ocupado, são unânimes em atribuir grande importância aos dinoflagelados pelágicos, colocando o grupo, por ordem de importância, logo a seguir ao das Diatomáceas, na escaia de elementos que contribuem poderosamente para fornecer alimento ans organismos marinhos, sobretudo aos de mar aberto. Kudo (1931, p. 97) declara que "os Dinoflagelados abundam no plancton marinho, desempenhando, no conjunto, importante papel na economia do mar". Mais recentemente Allen (1941, p. 610) diz parecer razoavel "dar aos dinoflagelados do planctcn, posição de destaque, sobretudo ao se recordar que contribuem amplamente para a subsistência de animais sedentários bem como aos de vida ativa". Diz ainda o mesmo autor que, além disso, a sua influência na oxigenação e em outras trocas de natureza química do mar é das mais importantes. 
O material que examinamos mensalmente é abundante e variado, figurando o gênero Ceratium, como um dos mais frequentes. Nêle encontramos um curioso exemplar que constitue objeto da presente nota e cujo estudo foi possivel graças aos recursos bibliográficos que nos foram fornecidos pela Biblioteca do Departamento de Zoologia, da Faculdade de Filosofia, Ciências e Letras, da Universidade de São Paulo.

T'emos, portanto, o prazer de agraciecer ao snr. Prof. Dr. Ernesto Marcus, Diretor do citado Departamento, as facilidades que nos foram proporcionadas para a consulta da literautra especializada sôbre o assunto.

Como é sabido, as variações especificas, no gênero Ceratium, são muito comuns. Em geral, porém, elas se apresentam, em maior ou menor amplitude, no ângulo antapical, originando prolongamentos de morfologia a mais diversa.

Descrevendo, por exemplo, Ceratium californiense, Kofold (1907, p. 302, pl. XXIII) nos fornece dois desenhos, em plano ventral, de exemplares que, à primeira vista, poderiam ser considerados como espécies diferentes. Em Cetatium inclinatum, o mesmo autor (1. c., p. 303, pl. XXV), diz que a simetria varia muito, apresentando ângulo antapical que oscila entre $60^{\circ}$ e o o que, alis, acontece tambem com C. ostenfeldi (1. c., p. 305, pil. XXVI) e com C. spirale (1. c., p. 305, pl. XXVII) .

Variações como essas, parecem ser frequentemente observadas no plancton de todos os mares do Universo, onde, não raro, encontram-se indivíduos cujas placas antapicais se acham partidas. Além diss?. constatam-se curiosos casos de exuviação, autotomia e regeneração, tais como os referidos por KofoID (1908, p. 345-386).

No material proveniente do litoral paulista, temos notado, às vezes. espessamento ou adelgaçamento das placas apicais, pré e post-cingulares, sendo porém mais frequente a observação de desvios acentuados do ângulo da placa antapical direita ou esquerda.

Até agora, tivemos ocasião de examinar 297 amostras do litoral bandeirante. sendo 153 de Santos e 144 do litoral sul do Estado (região lagunar Iguape-Cananéia). Desse material, efetuamos. até o presente, 29.700 contagens quantitativas, procedendo, concomitantemente, ao exame qualitativo do mesmo.

No que respeita aos Dinoflagelados, Ceratium furca é, sem dúvida, um dos representantes mais comuns da subordem Dinifera. No material correspondente à Estação n. ${ }^{\circ} 1$, da XI. ${ }^{n}$ viagem, de 26-5-1950 (Santos, N. ${ }^{\circ}$ de Ordem 94, da coleção do Instituto Paulista de Oceanografia), encontramos um único exemplar (Fig. 1) que chamou a nossa atenção pelo fato de possuir, no lado direito, um terceiro prolongamento suplementar, além das duas placas antapicais, apêndice êsse bem maior do que a terceira placa que caracteriza as espécies Cera- 
tium hirundinella e C. macroceros. O formato do espécime aproxima-se mais de Ceratium furca Dujardin var. baltica (Schutт 1895. pl. 9, fig. 36).
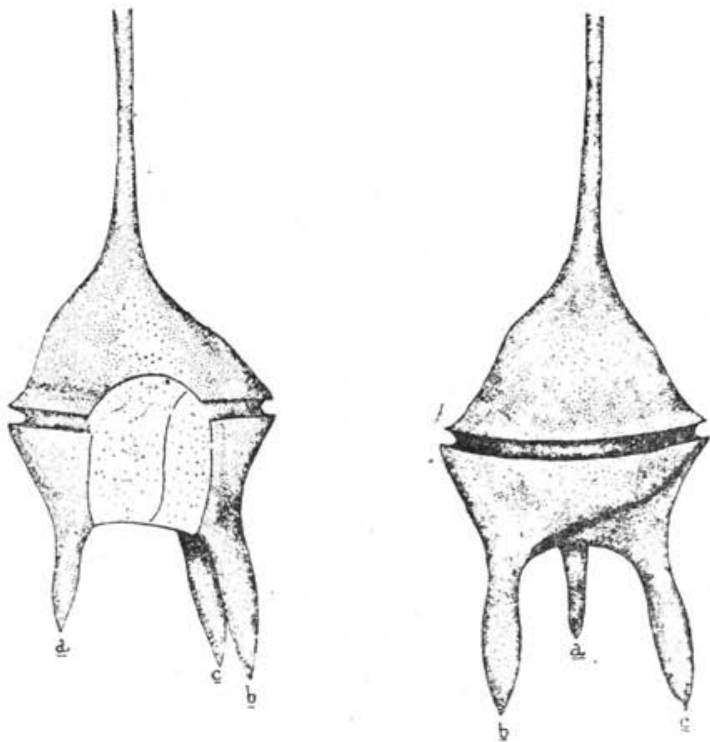

FrG. 1 - $a$ e $b$ placas antapicais, normais; $c$, placa ou prolongamento suplementar.

Sabe-se que várias condições do meio ambiente podem provocar modificações sensiveis nos corpos de certos organismos. As formas de inverno e verão de Bosmina e Ceratium são um exemplo dessa variação, tal como nô-la demonstraram WesENBERG-Lund (1937, p. 479, fig. 613) quando trataram de C. hirundinella, assunto também discutido por CARTER (1940, p. 143) e outros autores. Um dos exemplos típicos é o de Daphnia hyalina, cujo processo frontal varia de forma segundo as estações do ano, tornando-se mais comprida e portuda sob a influência da temperatura.

Já Reichenow (1929, p. 335) havia exposto amplamente a questão, referindo-se aos típos que SCHRÖDER designara pelos nomes de: furcoides, brachyceroides, silesiacum, cerianthiacum, austriacum, gracile, robustum, scotticum e piburgense. Diz o autor (1. c., p. $335)$ que "B. Schröder, por sua vez, constatou, da mesma espécie, nove típos que, independentemente de estações do ano ou temperatura, existem em lagos europeus e cujas divergências morfológicas devem provir ainda de outras causas. Variações semelhantes foram tambem observadas em Peridineos marinhos, por Schütt, Schimper, Chun, Carsten, podendo-se concluir que devem existir relações com a temperatura e com a salinirade da água". 
Até o momento, o exemplar que constitúe objeto da presente nota foi o único encontrado em 297 amostras provenientes de diferentes épocas do ano. A respeito da variação que nêle observamos, ainda nada se pode dizer. Pareceu-nos, no entretanto, que a ocorrência seria digna de registro.

\section{SUMÁRIO.}

Trata a presente nota do aparecimento de um exemplar de $\mathrm{Ce}$ ratium furca encontrado no plancton do litoral paulista, provido de $11 \mathrm{~m}$ terceiro prolongamento suplementar, ao lado da placa antapical direita.

O autor examina alguns casos de variações constatadas no mesmo gênero e regista o fato ocorrido no material proveniente do litoral paulista.

\section{ABSTRACT.}

The Marine Fauna Section of the Instituto Paulista de Oceanografia (São Paulo Oceanographic Institute), has undertaken regular ylankton researches along the coastal waters of São Paulo State (Brasil), as an index of their productivity.

After examining 297 superficial plankton samples from different areas and seasons, the author found a specimen of Ceratium that was considered very ciose to Ceratium furca Dujardin var. baltica (Fig. 1). whose occurrence called his attention due to the fact of having on its right side a third supplementary appendix longer than that of the characteristic plate of both species Ceratium hirundinella and macroceros.

Up to now, isolated individuals were observed with pre or post- cinguiar plates which exhibit a variable thikness. Frequently. were found somewhat strong deviations on the right or on the left side of the specimen examined.

Regarding the extra appendix considered here to be a specific variation, the author thinks that nothing definite can be said at present since only one such individual was caught. In the other hand he thinks that this specific variation is worthwhile noticing.

\section{BIBLIOGRAFIA.}

ALLEN, W. E., 1941 - 'Twenty year's statistical studies of marine plankton. Dinoflagellates of southern California. Amer. Midd. Nat., vol. 26, n. ${ }^{\circ}$, p. 603-635. Indiana.

CARTER, G. S., 1940 - A General Zoology of Invertebrates, XXVIII + 509 p. 172 figs. N. York. 
KOFOID, C. A., 1907 - Dinoflagellata of the San Diego Region. III Description of new species. Univ. Cal. Publ. Zoology, XVII, vol. 3, n. ${ }^{\circ} 13$, p. 299-340, pl. 22-23. Berkeley.

" " " 1908 - Exuviation, autotomy and regeneration in Ceratium. Univ. Cal. Publ. Zoology, vol. 4, n. 6 , p. 345-386. Berkeley.

KUDO, R. R., 1931 - Handbook of Protozoology, VII + 451 p. fig. 1-175. Springfield - Baltimore.

REICHENOW, E., 1929 - Lehrbuch der Protozoenkunde, VIII + 1262 p. Jena.

SCHÜTT, P., 1895 - Die Peridineen der Plankton-Expediticn. Ergebnisse der Plankton-Expedition der Humboldt Stiftung. I Theil, p. 1-170, taf. 127. Kiel und Leipzig.

WESENBERG-LLiND, C., 1937 - Ferskvandsfaunen Biologisk Belyst, vol. 2, p. 415-837. Copenhregen. 